\title{
MODELING OF DEFECTS IN ELECTRONIC NAVIGATION DEVICES OPERATING IN EXTREME CONDITIONS
}

\author{
Alexander Bogorosh ${ }^{1}$, Sergey Voronov ${ }^{2}$, Sergey Larkin $^{3}$, Vladimir Karachiun ${ }^{4}$, Nikolaj Vishniakov $^{5}$, \\ Jurij Novickij ${ }^{6}$, Danutė Ščkaturoviené ${ }^{7}$ \\ ${ }^{1-4}$ National Technical University of Ukraine "Kiev Polytechnic Institute",

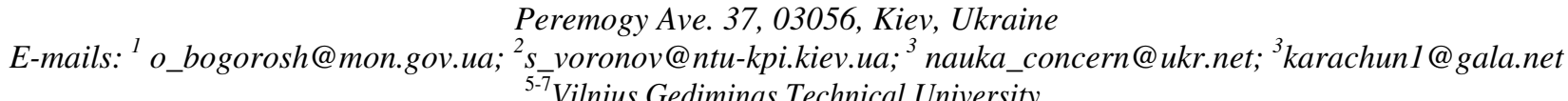 \\ ${ }^{5-7}$ Vilnius Gediminas Technical University, \\ Sauletekio al. 11, 10223 Vilnius, Lithuania \\ E-mails: ${ }^{5}$ nikvis@me.vgtu.lt; ${ }^{6}$ jurij.novickij@el.vtu.lt; ${ }^{7}$ danutes@me.vtu.lt
}

Received 23 February 2007; accepted 28 February 2008

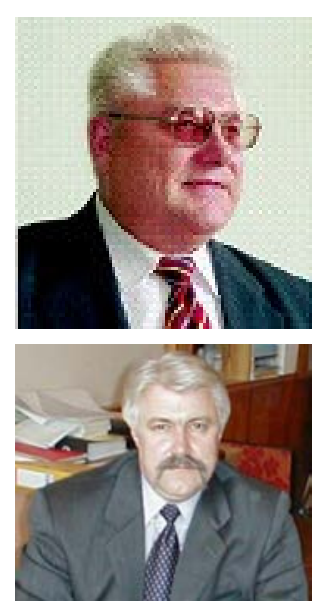

Alexander BOGOROSH, Prof Dr Habil

Present position: Professor of Department of Applied Physics, Chief Expert of Ministry for Education and Science of

Ukraine, Department of International S\&T Cooperation.

Organization address: National Technical University of Ukraine “KPI”, Kiev, 03224, Peremogy Ave. 37, Ukraine.

Phone: (38044) 24168 65; Fax: (38044) 2416029.

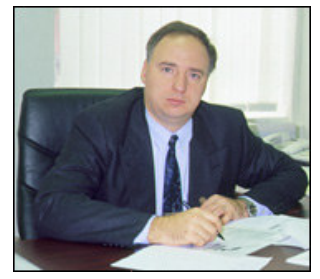

Sergey VORONOV, Prof Dr Habil

Present position: Head of Department of Applied Physics.

Organization address: National Technical University of Ukraine "KPI", Kiev, 03224, Peremogy Ave. 37, Ukraine

Phone: (38044) 45496 35; Fax: (38044) 2366029.

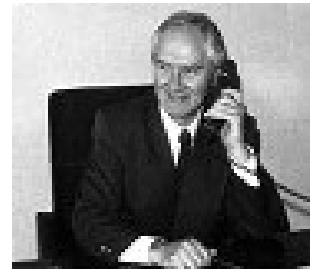

Sergey LARKIN, Dr

Present position: Director of Scientific and industrial concern "NAUKA".

Organization address: Scientific and industrial concern "NAUKA", 03148, Kiev, 50 Rokiv Jovtnya St. $2^{\mathrm{B}}$, Ukraine.

Phone: (38 044) 48205 11; Fax: (38044) 2387596.

Vladimir KARACHIUN, Prof Dr Habil

Present position: Head of Department of Biotechnology and Engineering, Academician of Ukrainian Aerospace Science Academy.

Organization address: National Technical University of Ukraine "KPI", 03056, Kiev-56, Peremogy Ave. 37, Ukraine. Phone: (38044) 241-68-83; Fax: (38044) 241-76-13. 


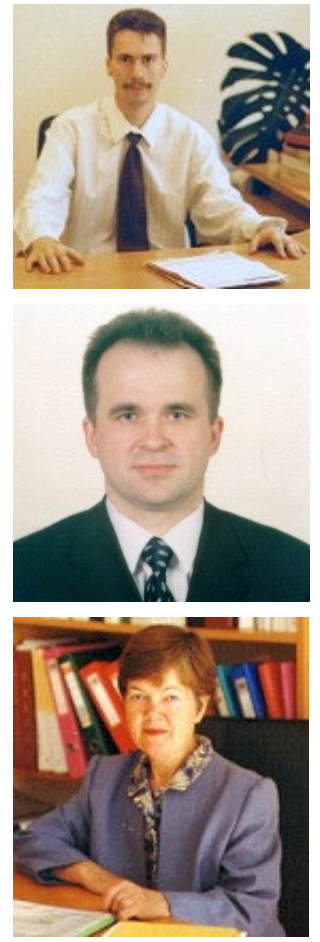

Nikolaj VISHNIAKOV, Dr

Present position: Director of Welding and Material Science Institute.

Organization address: Faculty of Mechanics, Vilnius Gediminas Technical University,

J. Basanavičiaus g. 28-1007, 03224 Vilnius, Lithuania.

Phone: +370 5 2745053; Fax: +370 52744740.

Jurij NOVICKIJ, Dr

Present position: Head of High Magnetic Field Laboratory, Assoc. Prof. of Department of Electrical Engineering Organization address: Faculty of Electronics, Vilnius Gediminas Technical University,

Naugarduko St. 41, LT-03227 Vilnius, Lithuania

Phone: +370 5 2744762; Fax: +370 52759501 .

\begin{abstract}
An investigation of the corrosive and mechanical destruction of microelectronic objects such as multipurpose sensors and navigating devices used in the airspace industry in extreme conditions such as variable temperature, pressure and environmental composition is described. The appearance and growth of micro cracks and other defects in metallic parts and conductors of micro devices due to external actions are investigated. The structural features of defect-testing devices improved on the basis of magnetic modulation sensitive iron elements are analyzed. Mathematical modeling for the most characteristic types of defects is performed and the forecast growth of defects within 6 $\%$ accuracy is achieved.
\end{abstract}

Keywords: defect detection, micro crack, mathematical fracture modeling.

\section{Introduction}

Modern mechanical engineering and the production of aircraft are impossible without the use of electronic multipurpose sensors and navigating devices. During operation, devices are affected by great mechanical (vibration), physical (variable temperature and pressure), chemical (composition of environment), and other kinds of overloads. These factors can destroy electronic navigating devices in which defects in the form of micro cracks grow at a height of two or more kilometers from the Earth. Such cracks cannot be diagnosed by usual methods after flights.

In previous research about the migration of atom clusters affected by the action of waves by means of an external physical field such as electro-sedimentation in a magnetic field, color pigment painting of optical glass with presence of colloidal metal particles in the paint, the absorption of nano-particles in a ceramic material matrix were demonstrated and research of stresses in the boards of micro modules caused by change in ambient pressure was carried out also [3]. In heterostructure quantum conductors, electron transmission through a linear molecule, non-localized and localized electronic states at formation of a current, and organic molecular structures and compositions were investigated [5, 2].

It is known that hydrogen is the basic element influ- encing metal components of materials in real conditions. Hydrogen has a minimal atomic size compared to other gases and it therefore easily penetrates into the cracks in the structure of metal. Due to the over active mobility of hydrogen getting into nodes of crystal lattice of a material, it supersedes the carbon, and due to the external wave affects local crystal and structural no heterogeneity is arisen and the migration of atom clusters becomes more active. This phenomena leads to brittleness and the formation of cracks in micro-devices. As a result of these factors, stresses reducing the reliability and durability of devices take place in certain parts of a material. Without protective coatings, this process is continuous and leads to the disintegration of the metal parts of objects. For many processes, including the hydrogen destruction of devices, pressure and temperature differences are dominant destructive factors, and non-stationary processes increase the activity of wave sign-variable external actions. Therefore devices affected by sign-variable values of temperature and pressure can be destroyed more quickly. The physical and chemical information about these processes collects in products of destruction (corrosion, deposits, and temper colors that allow one to restore a history of the process of destruction of an object. The objective of the present work is the investigation of destructive processes such as the appearance and further growth of micro cracks metal microstructures and con- 
ductors operated in extreme conditions. Ferro-modulation sensing elements (FMSE) were used to detect defects and changes of properties of conductors, heterostructures, and substrate materials operated under the influence of external physical and chemical action. The new solution to forecast destructions of micro objects is offered also.

\section{Subject and methodology}

For the diagnostics of micro cracks occurring in micro devices operated in extreme conditions, magnetic biasing coils can be used. The technique of a choice of optimum value of a field created by ferro-probe can be used for maintenance of a necessary FMSE sensitivity. The areas of defects at fields with maximal magnetic permeability, including cracks with displaced sides detected after soldering, welding and diffusive gluing, are the objects of this investigation. Components of navigating devices affected by vibrations, pressure, and signvariable changes of temperature from -40 to $+20^{\circ} \mathrm{C}$ are observed. Components and their destroyed samples with various defects such as micro cracks, hydrogen corrosion, tearing, radial sections of navigating devices contacts are analyzed. Destroyed contacts made from $\mathrm{Ti}_{8} \mathrm{C}_{12}$ and pressed vanadium carbide $\mathrm{VC}_{0,87}$ (grains from $50 \mathrm{~nm}$ up to $50 \mu \mathrm{m})$ are investigated. The investigation of the topography of sections of micro conductors with thickness of about $0.1 \mathrm{~mm}$ shows a variety of forms of microdefects in Ti or $\mathrm{V}$ metal caused by corrosion, mechanical factors, and other physical and chemical factors. Microdefects can be grouped into four basic types.

The first type. The initial stage of corrosion is related to the formation of micro cracks set around the borders of grains and atomic hydrogen enters deeply into the metal (Fig 1).

In places with natural structural anomalies in the metal hydrogen concentrates and this leads to the expansion of micro-cracks (Fig 2).

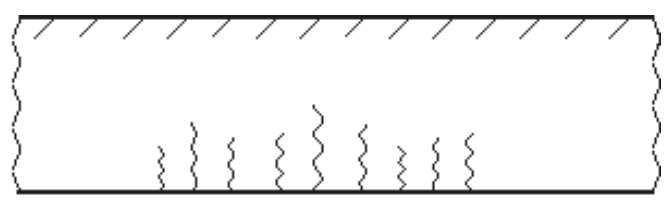

Fig 1. Initial stage of defect - micro crack propagation on all internal surfaces of object

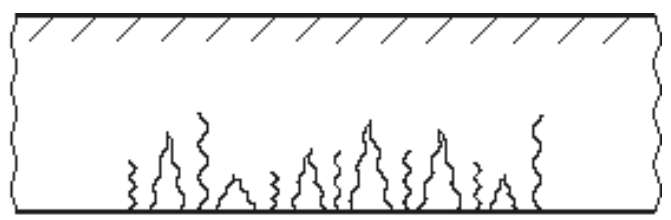

Fig 2. Expansion of cracks through imperfection in crystal lattices of metal of object

The second type. Under hydrogen pressure inside the crack of an object and under atmospheric/environmental pressure (differential), isolated defects merge and form internal cavities with depths up to 100 nanometers (Fig 3). They provide hydrogen and other corrosive me- dium to "fresh metal" that leads to the continuation of the destruction process. The greatest intensity of defect propagation is observed in the top of each cavity (Fig 4).

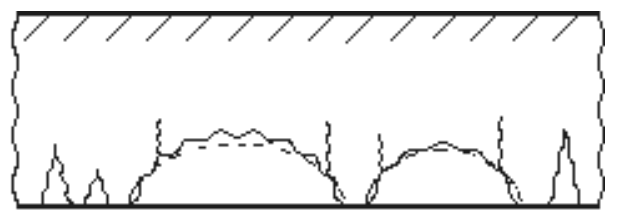

Fig 3. Merge of micro racks into local cavities

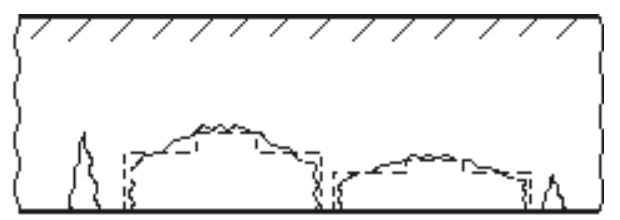

Fig 4. Formation of cavities in the form of a rectangular step The third type. As defect propagation most intensively goes in a direction perpendicular to internal surface of wall (Fig 5).

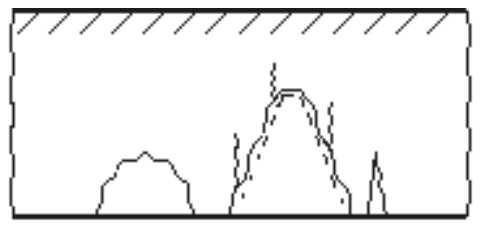

Fig 5. Subsequent propagation of hydrogen corrosion defect, which is nearing a conic form

Then the defect approaches the external wall of micro-conductor, the destroying action due to the difference of environment pressure and regarding the mismatch of mechanical stresses on the protected and uncovered surfaces has arisen and crack increases. As a result, the defect takes on a nearly rectangular form (Fig 6).

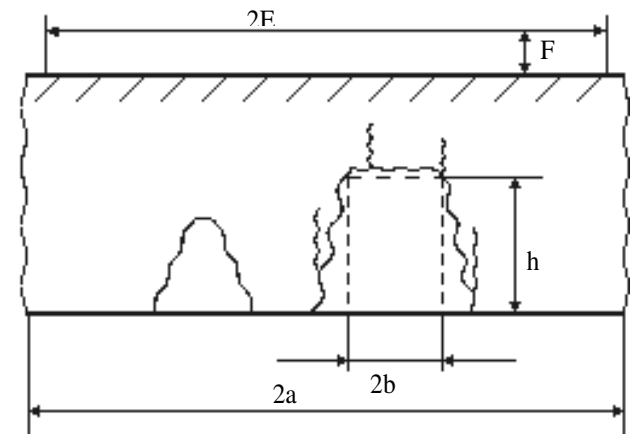

Fig 6. Computational model of subsurface hydrogen corrosion defect

The fourth type. At more intensive destruction, the rectangular defect can evolve into a parallelogram with straight or gear-shaped planes on the small sides and parallel planes on the bigger sides. Cross-sections of defects such as inclined and gear forms are shown below (Figs 7, 8). 


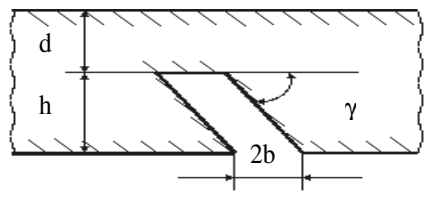

Fig 7. Cross-section of inclined defect

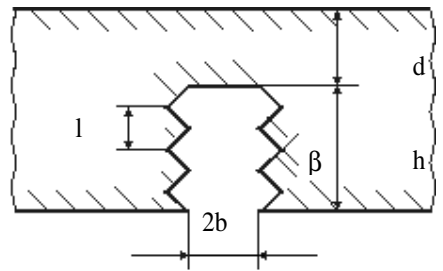

Fig 8. Cross-section of gear form defect

\section{Mathematical modeling}

For a mathematical description of external and internal defects, it is possible to use a geometrical model of the sample with a defect at the depth of $d$ or the height of $h$ (Figs 9, 10).

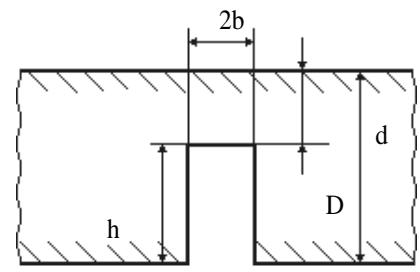

Fig 9. Geometrical model of subsurface defect

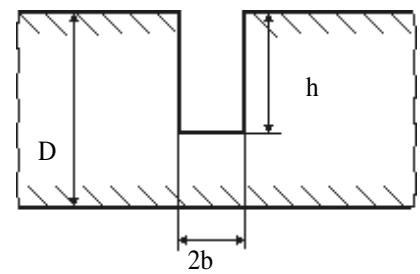

Fig 10. Geometrical model of surface defect

For the diagnostics of micro cracks, magnetic biasing coils combined with the technique of a choice of optimum value of a field created by ferro-probe for the maintenance of a necessary threshold of FMSE sensitivity are used also [4, 1].

These techniques have the following differences: biasing coils have six sections (instead of three) with different value of current in each of them to get a homogeneous magnetic field $B$ as shown in figure 11 .

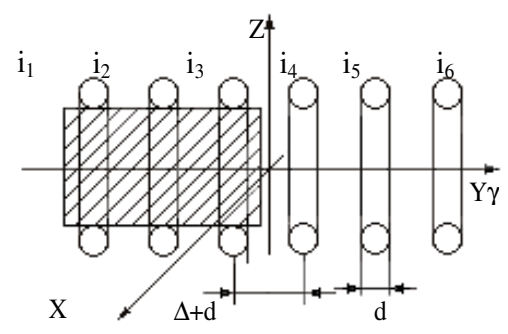

Fig 11. Replacement of three-section coil to six-section coil with infinitely thin conductors
The volume $V_{M}$ with sizes along axes $x, y, z$ are $2 a$, $2 b, 2 c$ in the section having rectangular form. Homogeneous magneto static field directed along axis $y$, is generated as shown in figure 12.

For the creation of six section coils, the virtual method of mirror reflection that raises FMSE sensitivity up to three orders has been used. The mathematical model is used as set $N$ of infinitely thin electromagnetic coils with the turns of the rectangular form laying in a plane of sections parallel to axes $x 0 z$. The thickness of coil sections and clearances between them are designated $d_{j}(j=\overline{1, N})$ and $d_{j}>0 ; D_{j} \geq 0$.

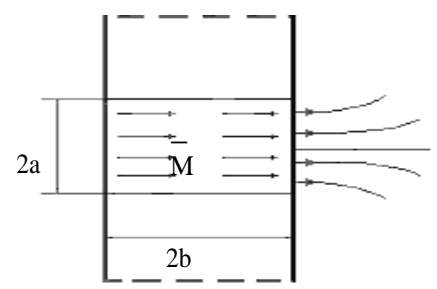

Fig 12. Scheme of a magnetic flux in volume $V_{M}$ from six sections along an axis

As were shown in figure 11 , the case at identical $d_{j}$ and $D_{j}$ is presented. This means all thin coils are made of a wire of one cross-section. Then the number of turns of thin coils $W_{l}, W_{2}, \ldots, W_{N}$ will be required. Another difference is that initially currents $i^{(1)} i_{1}, i^{(1)} i_{2} . ., i^{(1)} i_{N}$ of infinitely thin rectangular turns, the sizes of which along axes $x$ and $z$ are equal to the internal sizes of designed thin coils, are defined. It is obvious, that:

$$
y_{j}=-b+\frac{d}{2}+(d+\Delta)(j-1) ; j=\overline{1, N}
$$

Further, according to Bio-Savare-Laplace formulas, it is possible to find a step-by-step current induction of $j$ th turn in volume $V_{M}$ :

$$
\begin{aligned}
& \bar{B}_{j}^{(1)}(x, y, z)=\frac{\mu_{0}}{4 \pi}\left[\frac{Y_{j}}{x_{j-}^{(1) 2}+Y_{j}^{2}}\left(\frac{z_{j+}^{(1)}}{r_{3 j}^{(1)}}-\frac{z_{j-}^{(1)}}{r_{2 j}^{(1)}}\right)-\frac{Y_{j}}{x_{j+}^{(1) 2}+Y_{j}^{2}}\left(\frac{2_{j+}^{(1)}}{r_{4 j}^{(1)}}-\frac{z_{j-}^{(1)}}{r_{1 j}^{(1)}}\right)\right] \overline{1}_{\alpha} \\
& +\left[\frac{z_{j-}^{(1)}}{Y_{j}^{2}+z_{j-}^{(1) 2}} \times\left(\frac{x_{j-}^{(1)}}{r_{2 j}^{(1)}}-\frac{x_{j+}^{(1)}}{r_{1 j}^{(1)}}\right)+\frac{x_{j-}^{(1)}}{x_{j-}^{(1) 2}+Y_{j}^{2}}\left(\frac{z_{j-}^{(1)}}{r_{2 j}^{(1)}}-\frac{j_{-}^{(1)}}{r_{3 j}}\right)\right. \\
& \left.+\frac{z_{j+}}{Y_{j}^{2}+z_{j+}^{(1) 2}}\left(\frac{x_{j+}^{(1)}}{r_{4 j}^{(1)}}-\frac{x_{j-}^{(1)}}{r_{2 j}^{(1)}}\right)+\frac{x_{j+}^{(1)}}{x_{j+}^{(1) 2}+Y_{j}^{2}} \times\left(\frac{z_{j+}^{(1)}}{r_{4 j}^{(1)}}-\frac{z_{j-}^{(1)}}{r_{1 j}^{(1)}}\right)\right]+ \\
& {\left[\frac{Y_{j}}{Y_{j}^{2}+z_{j-}^{(1) 2}}\left(\frac{x_{j+}^{(1)}}{r_{1 j}^{(1)}}-\frac{x_{j-}^{(1)}}{r_{2 j}^{(1)}}\right)+\frac{Y_{j}}{Y_{j}^{2}+z_{j+}^{(1) 2}}\left(\frac{x_{j-}^{(1)}}{r_{3 j}^{(1)}}-\frac{x_{j+}^{(1)}}{\left.r_{4 j}^{(1)}\right)}\right)\right] \overline{1}_{z}} \\
& x+a_{j}^{(1)}=x_{j+}^{(1)}, x-a_{j}^{(1)}=x_{j-}^{(1)}, y-y_{j}=Y_{j}, \\
& z+c_{j}^{(1)}=z_{j+}^{(1)}, z-c_{j}^{(1)}=z_{j-}^{(1)} ; \\
& r_{1 j}^{(1)}=\sqrt{x_{j+}^{(1) 2}+Y_{j}^{2}+z_{j-}^{(1) 2}}, r_{2 j}^{(1)}=\sqrt{x_{j-}^{(1) 2}+Y_{j}^{2}+z_{j-}^{(1) 2}} \\
& r_{3 j}^{(1)}=\sqrt{x_{j-}^{(1) 2}+Y_{j}^{2}+z_{j+}^{(1) 2}}, r_{4 j}^{(1)}=\sqrt{x_{j+}^{(1) 2}+Y_{j}^{2}+z_{j+}^{(1) 2}},
\end{aligned}
$$

where the field in volume $V_{M}$ is designated by points. Points $i_{j}^{|1|}(j=\overline{1, w})$ are under condition: 


$$
\left\|\bar{B}(x, y, z)-\sum_{j=1}^{N} i_{j}^{(1)} B_{j}^{(1)}(x, y, z)\right\|=\min .
$$

The solution of problem (3) is reduced to the known system of the linear algebraic equations:

$$
\sum_{j=1}^{N}\left(\bar{B}_{j}^{(1)}, \bar{B}_{k}^{(1)}\right) i_{j}^{(1)}=\left(\bar{B}, \bar{B}_{k}^{(1)}\right), k=\overline{1, w} .
$$

Then the solution of system (4) will be a set of micro-currents $i_{1}^{(1)}, i_{2}^{(1)} K i_{N}^{(1)}$. After that it is possible to find a magnetic field of these micro-currents $B_{N}^{(1) 2}(x, y, z)$, and also an error $\eta_{N}^{(1)}=\left\|\bar{B}-\bar{B}_{N}^{(1)}\right\| /\|\bar{B}\|$.

The system of the linear equations is formed by definition of the scalar product in Hilbert space:

$$
(\bar{v} \cdot \bar{u})=\int_{V_{M}} \bar{v}(x, y, z) u(x, y, z) d V
$$

The first approximation of the set of thin coils is defined, i.e. currents are distributed in sections of thin coils depending on spatial factors. As a result, the sizes of coils are defined, i.e. $h_{1}^{(1)}, h_{2}^{(1)} K h_{N}^{(1)}$.

Directions of current density in thin coils (for the first approximation) are defined by signs of currents $i_{j}^{(1)}$. If $i_{j}^{(1)}>0$, then current density in the top intersection of the $j$-th thin coil is directed along axis $x$, and if $i_{j}^{(1)}<0-$ against an axis $x$. When first approximation of parameters of set of thin coils is carried out, magnetic field in volume $V_{c}$, created by these coils $B^{(1)}(x, y, z)$ and an error $\eta^{(1)}=\left\|\bar{B}-\bar{B}^{(1)}\right\| /\|\bar{B}\|$ can be defined according to formula (5). If this error exceeds $\eta_{N}^{(1)}$, it is necessary to execute the second approximation, having infinitely thin rectangular coils. Then, the distribution of currents in the sections of thin coils should be defined. The size $h_{j}^{(1)}$ increases if currents $i_{j}^{(1)}$ and $i_{j}^{(2)}$ have one sign and it decreases otherwise. An iterative process can be finished after $n$-th step when the approximate equality $\eta^{(n)}=\eta_{N}^{(n)}$ is accessed. As was considered before, a one component of a magnetic induction $\bar{B}=\bar{l}_{y} B_{0}$ is specified in the six points and is shown in figure 13 .

The equations system can be presented in this form:

$\left[\begin{array}{lccccc}B_{1 y}^{(1)} \cdot B_{1 y}^{(1)} & B_{2 y}^{(1)} \cdot B_{1 y}^{(1)} & B_{3 y}^{(1)} \cdot B_{1 y}^{(1)} & B_{4 y}^{(1)} \cdot B_{1 y}^{(1)} & B_{5 y}^{(1)} \cdot B_{1 y}^{(1)} & B_{6 y}^{(1)} \cdot B_{1 y}^{(1)} \\ B_{1 y}^{(1)} \cdot B_{2 y}^{(1)} & B_{2 y}^{(1)} \cdot B_{2 y}^{(1)} & B_{3 y}^{(1)} \cdot B_{2 y}^{(1)} & K & K & K \\ M & & & & & \\ M & & & & & \\ M & & & & & \\ B_{1 y}^{(1)} \cdot B_{6 y}^{(1)} & B_{2 y}^{(1)} \cdot B_{6 y}^{(1)} & B_{3 y}^{(1)} \cdot B_{6 y}^{(1)} & B_{4 y}^{(1)} \cdot B_{6 y}^{(1)} & B_{5 y}^{(1)} \cdot B_{6 y}^{(1)} & B_{6 y}^{(1)} \cdot B_{6 y}^{(1)}\end{array}\right]\left[\begin{array}{l}i_{1} \\ i_{2} \\ M \\ M \\ M \\ i_{6}\end{array}\right]=\left[\begin{array}{l}B_{1 y} \cdot B_{0} \\ B_{2 y} \cdot B_{0} \\ M \\ M \\ M \\ B_{6 y} \cdot B_{0}\end{array}\right]$

With the use of the suggested technique, the calculation of systems of magnetic biasing coils with the following parameters is performed: $h=0.25 \mathrm{~mm}, a=b=0.01$ mm. In volumes $0.25 \mathrm{~mm}^{3}, 0.17 \mathrm{~mm}^{3}$ and $0.1 \mathrm{~mm}^{3}$, a homogeneous magnetic field with the induction vector $B$ $=0.1 \mathrm{~T}$ was synthesized. As a result, the following values of currents $i_{1}=3.010^{3} \mathrm{~A}$ are received: $i_{2}=4.410^{3} \mathrm{~A} ; i_{3}=$ $5.3 \cdot 10^{3}$ A. The error of calculation does not exceed $\eta=6$ $\%$.

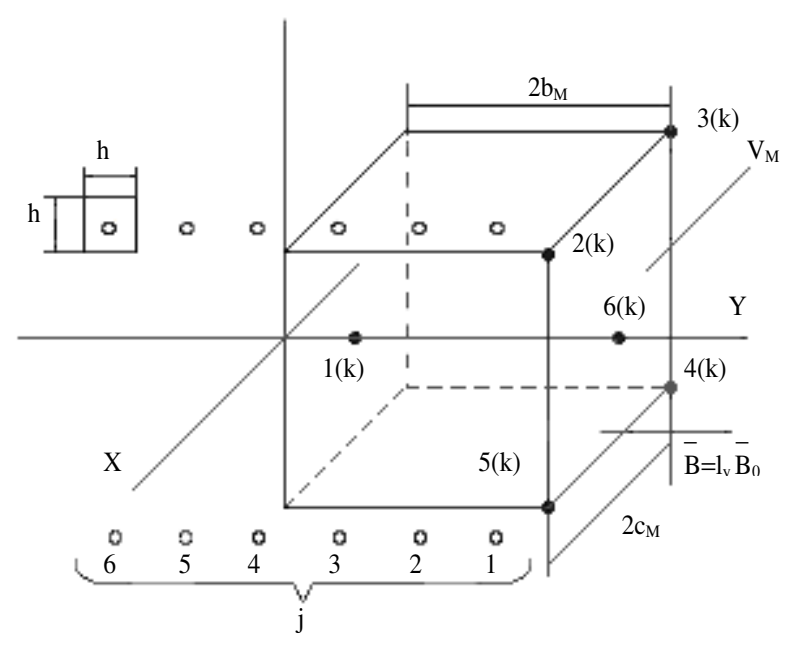

Fig 13. Explanatory scheme for formation of linear equations system

\section{Experimental results}

During corrosion cracks and defects having a complex profile of cross-section can be observed. They are not inclined by the surface to a substrate only, but also the inclination angle repeatedly changed during development of defect inside of material can be found (Fig 14)

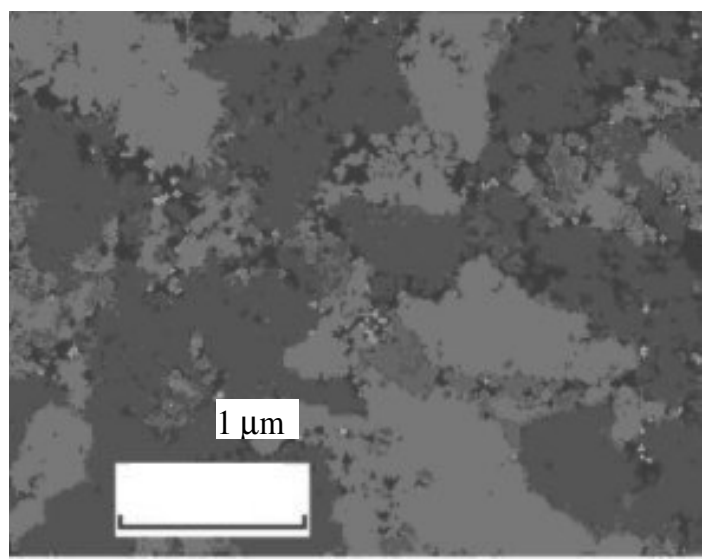

Fig 14. Grains of pressed vanadium carbide $\mathrm{VC}_{0.875}$. Hydrogen corrosion due to steady and pulse irradiation $(\eta=22 \mathrm{kHz}, I=20$

$\mathrm{W} / \mathrm{sm}^{2}, \tau=720$ hour). Bright grey area - grains, dark grey oxide cavities

Areas with defects having maximal magnetic permeability, including cracks with displaced sides detected after soldering, welding, and diffusive gluing of a seam, were studied instead of modeling. Data about the distribution of cracks with a deviation to the left, to the left and at depth and at depth have a similar character (Fig 16; a,b,c) This was confirmed by direct microscopic measurements (at corresponding points) (Fig 15). 


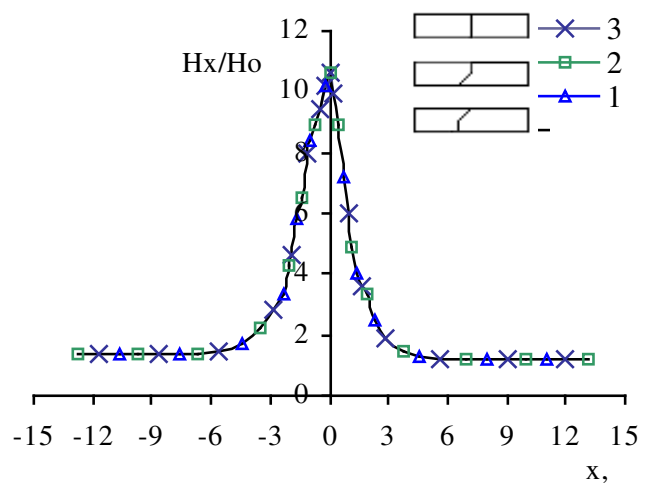

Fig 15. Dependence $H_{x}(x)$ for three types of defects $x, \mu$ m. $\mathrm{nm}$; $2 b=0.2 \mathrm{~nm}$ ) in a magnetic field $y=1.0 \mathrm{~nm}, H=10 \mathrm{~A} / \mathrm{sm}$
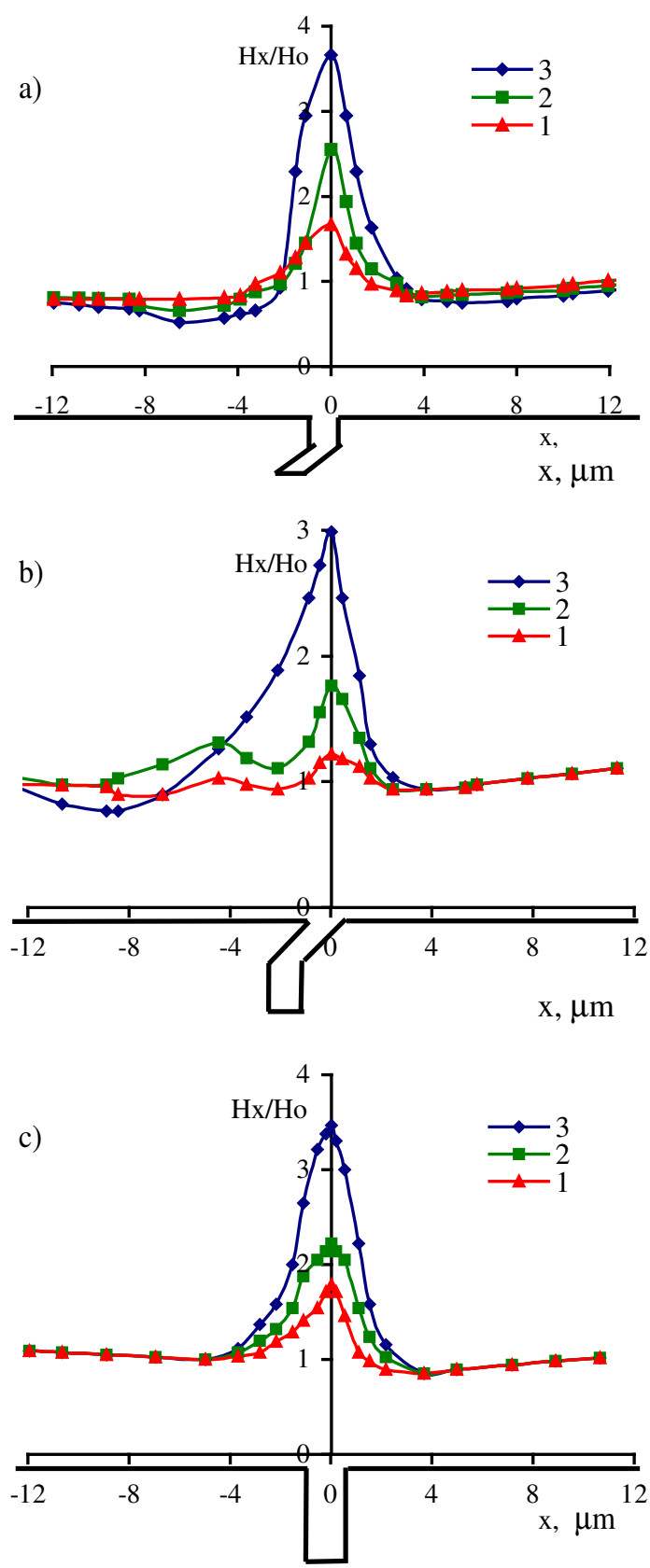

Fig 16. Topography of area with different types of defect $(h=4 \mathrm{~nm}$; for $1-2 b=0.025 \mathrm{~nm} ; 2-2 b=0.08 \mathrm{~nm} ; 3-2 b=$ $0.2 \mathrm{~nm}$; magnetic intensity on the surface $\mathrm{MH}: H=10 \mathrm{~A} / \mathrm{cm}$ )

\section{Summary and conclusions}

The investigation of the corrosive and mechanical destruction of devices such as multipurpose sensors and navigating devices used in the aerospace industry and operated in extreme conditions such as highly variable temperature, pressure and environmental composition is done. According to applied results it is possible to declare that for the supervision and control of damage level of devices magneto static methods with application ofusing FMSE matrixes are applicable. The diagnostics of the destruction of micro objects can be carried out using a mathematical model with the subsequent solution of corresponding problems and the transition from known differential equations of an electromagnetic field to the integral kind based on Green's identities. This model allows to predict the occurrence of a micro crack and to estimate the direction of propagation during the operation of devices. In the general statement of a problem the calculation of physical fields is applied to objects with significant weight of metal and thickness of substrates (weight not less than $1 \mathrm{~g}$ and thickness of substrate more than 500 $\mathrm{nm})$. Therefore, for detection of micro cracks, defects and other diagnostics on micro objects with an area from 1-2 $\mathrm{mm}^{2}$ and layer thickness from 0.2 to $10 \mathrm{~nm}$, other concept of modeling for forecasting processes of the destruction of micro/nano objects should be done. Higher sensitivity of specially created devices is also required. The mathematical modeling for the most characteristic types of defects is performed and the forecast growth of defects within $6 \%$ accuracy is achieved.

\section{References}

1. Miroshnikov, V. V. 2000. Experimental research of dissipation magnetic fields around defects. In The Bulletin of East Ukrainian National University. Lugansk, vol. 32, no. 10, 154-158.

2. Petrov, E. G. 2005. Transmission of electrons through a linear molecule: The role of non-localized and the localized electronic states in current formation. Physics of Low Temperatures, 31(3/4): 445462.

3. Roizman, V. P.; Strelbickij, V. V. 2006. Experimental research of the stresses in micro modules boards at change of atmospheric pressure. In The Bulletin of Khmelnickiy National University, vol. 1, 206-207.

4. Tozoni, O. V.; Romanovich, S. S. 1975. About calculation of permanent magnets on computer. In The Bulletin of High Schools. Electro mechanics, no. 8, 818-826.

5. Viduta, L. V.; Kniazev, O. E.; Marchenko, A. A. et al. 2005. Research of electrophysical and luminescent properties of metal-organic nanocomposites. Nanosistems, Nanomaterials, Nanotechnologies, 3(3): 1001-1010. 
DEFEKTU MODELIAVIMAS NAVIGACIJOS ELEKTRONINIUOSE PRIETAISUOSE, EKSPLOATUOJAMUOSE EKSTREMALIOMIS SĄLYGOMIS

A. Bogorosh, S. Voronov, S. Larkin, V. Karachiun, N. Vishniakov, J. Novickij, D. Ščekaturovienė

S a n tra k a

Atlikti mikroelektronikos objektų, eksploatuojamų ekstremaliomis sąlygomis bei esant kintamoms temperatūroms, slègiui, darbinės aplinkos suděčiai, irimo tyrimai, tarp jų - mikroịtrūkimų ir kitų defektų atsiradimo bei augimo mikroprietaisų metalinėse dalyse ir laidininkuose. Pagerinti prietaisų, gaminamų fero-moduliacinių elementų pagrindu ir skirtų mikroprietaisų defektų kontrolei, konstruktyviniai sprendimai. Sudarytas matematinis modelis, leidžiantis analizuoti būdingiausių rūšių defektus ir iki $6 \%$ tikslumu prognozuoti defektų plitimą.

Reikšminiai žodžiai: defektų detektavimas, mikroịtrūkimas, matematinis įtrūkimų modeliavimas. 